\title{
Separations Needs for the Alternate Chemical Cycles
}

\author{
Frederick F. Stewart
}

May 2007

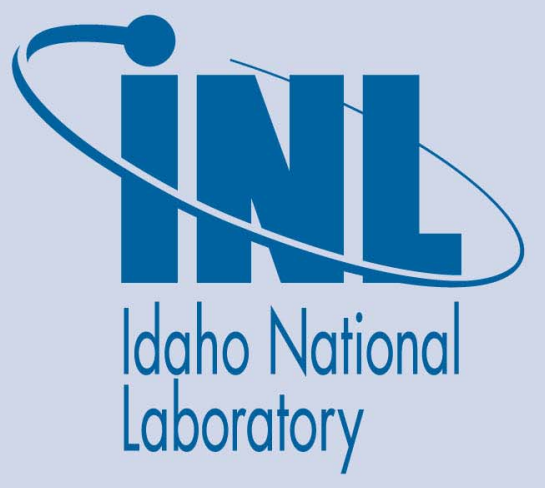

The INL is a U.S. Department of Energy National Laboratory operated by Battelle Energy Alliance 

INL/EXT-07-13619

\title{
Separations Needs for the Alternate Chemical Cycles
}

\author{
Frederick F. Stewart
}

May 2007

\author{
Idaho National Laboratory \\ Chemical Sciences Department \\ Idaho Falls, Idaho 83415
}

Prepared for the

U.S. Department of Energy

Office of Nuclear Energy

Under DOE Idaho Operations Office

Contract DE-AC07-05ID14517 
This page intentionally left blank. 


\begin{abstract}
The bulk of the efforts for the development of a hydrogen production plant supported by the Nuclear Hydrogen Initiative (NHI) have been directed towards the sulfur-iodine (S-I) thermochemical cycle. However, it was judged prudent to re-investigate alternate chemical cycles in light of new developments and technical accomplishments derived from the current S-I work. This work analyzes the available data for the promising alternate chemical cycles to provide an understanding of their inherent chemical separations needs. None of the cycles analyzed have separations that are potential "show stoppers"; although some of the indicated separations will be challenging to perform. The majority of the separations involve processes that are either more achievable or more developed.
\end{abstract}


This page intentionally left blank. 


\section{CONTENTS}

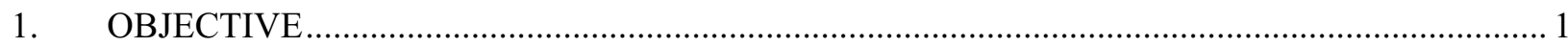

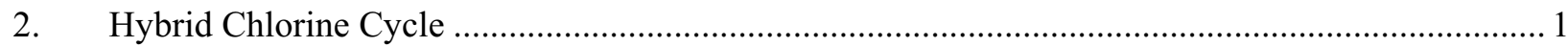

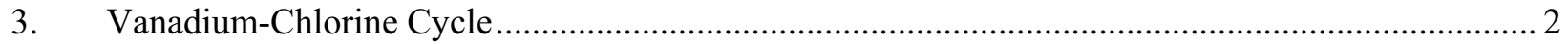

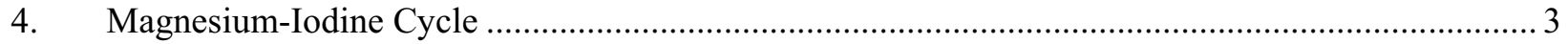

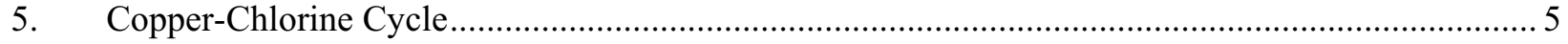

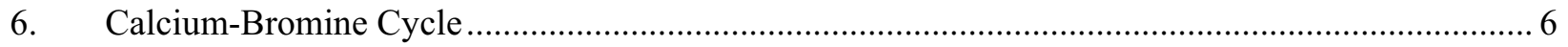

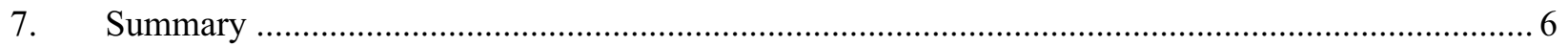


This page intentionally left blank. 


\section{OBJECTIVE}

The bulk of the efforts for the development of a hydrogen production plant supported by NHI have been directed towards the sulfur-iodine (S-I) thermochemical cycle. However, it was judged prudent to re-investigate the more promising alternate chemical cycles in light of new developments and technical accomplishments derived from the current S-I work. In this work, we have sought to analyze the available data for the promising alternate chemical cycles to provide an understanding of their inherent chemical separations needs. However, it should be noted that this report is not intended to be all inclusive due to the fact that physical conditions of each of the processes may be varied as the cycles are developed. Large modifications can create separations issues that are not anticipated in this report.

\section{Hybrid Chlorine Cycle}

The hybrid chlorine cycle employs two main reactions. The first, the reverse Deacon reaction (eq 1), converts elemental chlorine and water into $\mathrm{HCl}$ and oxygen. Oxygen is removed from the process and the $\mathrm{HCl}$ is decomposed through electrolysis yielding $\mathrm{H}_{2}$ as the desired product and $\mathrm{Cl}_{2}$ gas, which is recycled to the reverse Deacon reaction.

$\mathrm{Cl}_{2}(\mathrm{~g})+\mathrm{H}_{2} \mathrm{O}(\mathrm{g}) \leftrightarrow 2 \mathrm{HCl}(\mathrm{g})+1 / 2 \mathrm{O}_{2}(\mathrm{~g}) \quad 850{ }^{\circ} \mathrm{C} \quad$ eq 1

$2 \mathrm{HCl}(\mathrm{g}) \leftrightarrow \mathrm{H}_{2}(\mathrm{~g})+\mathrm{Cl}_{2}(\mathrm{~g})$ electrolytic $\quad 75^{\circ} \mathrm{C} \quad$ eq 2

The Gooding group at Clemson University has recognized that the separation of $\mathrm{O}_{2}$ from $\mathrm{HCl}$ (and remaining $\mathrm{Cl}_{2}$ and water) is perhaps the most significant issue and they propose that this can be accomplished using dense ceramic membrane for the removal of $\mathrm{O}_{2}$, or by using an acidic absorber to remove $\mathrm{HCl}$. For their experimental studies of this cycle, they have concentrated on the $\mathrm{HCl}$ absorber technology. However, this approach requires a desorption step to affect recycle of the acid to the reverse Deacon reactor.

Selective oxygen membrane technology has been demonstrated using mixed metal oxide substrates. Mixed metal membranes are of interest for this project due to the expected resistance they should have to both high temperatures and oxidative chemical environments. The first report of a mixed metal oxide membrane exhibiting high oxygen permeability was published in 1985. ${ }^{\mathrm{a}} \mathrm{A}$ more recent paper discussed in detail a method for forming mixed $\mathrm{Sr}, \mathrm{Co}, \mathrm{Fe}$ (SCFO) and $\mathrm{Ba}, \mathrm{Sr}, \mathrm{Co}, \mathrm{Fe}$ (BSCFO) oxide membranes. ${ }^{\mathrm{b}}$ The metals were mixed together in aqueous solution as nitrate salts in EDTA and citric acid. Ammonia was added to adjust the $\mathrm{pH}$ and the solvent was evaporated to yield a purple gel. The gel was then heated to $150{ }^{\circ} \mathrm{C}$ to make a powder that was calcined at $950^{\circ} \mathrm{C}$. Membranes were formed from the powders using a hydraulic press. The membrane disks were then sintered at $1150^{\circ} \mathrm{C}$ for $2-5$ hours yielding a membrane suitable for gas permeance study.

\footnotetext{
${ }^{a}$ Y. Teraoka, H.M. Zhang, S. Furukawa, and N. Yamazoe, “Oxygen Permeation Through Perovskite-Type Oxides”, Chem. Lett. $1985,1743$.

${ }^{\mathrm{b}}$ Z. Shao, W. Yang, Y. Cong, H. Dong, J. Tong, and G. Xiong, "Investigation of the Permeation Behavior and Stability $\mathrm{Ba}_{0.8} \mathrm{Sr}_{0.5} \mathrm{Co}_{0.8} \mathrm{Fe}_{0.2} \mathrm{O}_{3-\delta}$ Oxygen Membrane”, J. Membr. Sci. 2000, 172, 177.
} 
Membranes that were $1.5 \mathrm{~mm}$ thick were examined for $\mathrm{O}_{2}$ permeability. The authors noted that brittleness was a factor in experiments where the temperature was increased to $600{ }^{\circ} \mathrm{C}$ followed by controlled cooling at $1{ }^{\circ} \mathrm{C} / \mathrm{min}$. The BSCFO membrane showed less cracking than the SCFO membrane, suggesting that the BSCFO material has a lower expansion coefficient and better dimensional stability. Both formulations showed direct proportionality between the operating temperature and the $\mathrm{O}_{2}$ flux. At $600{ }^{\circ} \mathrm{C}$, both materials had measured $\mathrm{O}_{2}$ fluxes of 0.1 $\mathrm{mL} / \mathrm{cm}^{2} \mathrm{~min}$. As the temperature was increased to $800^{\circ} \mathrm{C}$, permeability of $\mathrm{O}_{2}$ increased to approximately $1.3 \mathrm{~mL} / \mathrm{cm}^{2} \min$ for the SCFO membrane and $1.5 \mathrm{~mL} / \mathrm{cm}^{2} \min$ for the BSCFO membrane.

$\mathrm{O}_{2}$ permeation also showed a positive correlation to the feed-side pressure using a 1.8 mm thick membrane. At $950{ }^{\circ} \mathrm{C}$, a feed pressure of $0.01 \mathrm{~atm}(0.15 \mathrm{psi})$ yielded a permeability of $0.13 \mathrm{~mL} / \mathrm{cm}^{2} \mathrm{~min}$. As the pressure was raised to $1 \mathrm{~atm}(14.9 \mathrm{psi})$, the permeability was measured at $2.1 \mathrm{~mL} / \mathrm{cm}^{2} \mathrm{~min}$. BFSCO membrane durability tests showed good high temperature performance and little loss of transmembrane flux at $850{ }^{\circ} \mathrm{C}$, suggesting that this particular formulation was quite stable.

\section{Vanadium-Chlorine Cycle}

This cycle is considered in this analysis because of its dependence on the reverse Deacon reaction. The Vanadium-chlorine cycle is a purely thermochemical cycle based upon the reverse Deacon reaction and the oxidation-reduction chemistry of vanadium. One variant of the cycle consists of one low temperature reaction, one moderate temperature, and two high temperature steps. $^{\mathrm{c}}$
$2 \mathrm{VCl}_{2}+2 \mathrm{HCl}(\mathrm{g}) \leftrightarrow 2 \mathrm{VCl}_{3}+\mathrm{H}_{2}(\mathrm{~g})$
$25^{\circ} \mathrm{C}$
eq 3
$4 \mathrm{VCl}_{3}(\mathrm{~s}) \leftrightarrow 2 \mathrm{VCl}_{4}(\mathrm{~g})+2 \mathrm{VCl}_{2}(\mathrm{~s})$
$750^{\circ} \mathrm{C}$
eq 4
$2 \mathrm{VCl}_{4}(\mathrm{l}) \leftrightarrow 2 \mathrm{VCl}_{3}+\mathrm{Cl}_{2}(\mathrm{~g})$
$200{ }^{\circ} \mathrm{C}$
eq 5
$\mathrm{Cl}(\mathrm{g})+\mathrm{H}_{2} \mathrm{O}(\mathrm{g}) \leftrightarrow 2 \mathrm{HCl}(\mathrm{g})+1 / 2 \mathrm{O}_{2}$
$850^{\circ} \mathrm{C}$
eq 6

This cycle has several chemical separations that need to be performed to make the cycle a success. The separations issues discussed with respect to the hybrid chlorine cycle and the reverse Deacon reaction apply here. In a patent application discussing the $\mathrm{V}-\mathrm{Cl}$ cycle by Amendola, a sorbent is used to selective remove the $\mathrm{HCl}$ from $\mathrm{O}_{2}{ }^{\mathrm{d}}$ Liquid amine containing organic sorbents such as monoethanolamine reversibly form complexes with $\mathrm{HCl}$. $\mathrm{HCl}$ can be recovered by heating. An advantage of $\mathrm{HCl}$ removal is that it shifts the equilibrium of the reverse Deacon reaction, thus encouraging increased conversion.

\footnotetext{
${ }^{c}$ M. Lewis, "Down Selection of the Four Most Promising Alternative Thermochemical Cycles", Milestone report, Nuclear Hydrogen Initiative, March 31, 2007.

d S. Amendola, "Thermochemical Hydrogen Produced from a Vanadium Decomposition Cycle", U.S. Patent Application 2005/0013771 A1, January 20, 2005.
} 
Although not explicitly shown in equations 3-6, water management is an issue that must be addressed. ${ }^{\mathrm{e}}$ In eq. 3, the $\mathrm{HCl}$ is aqueous and hydrates the vanadium(III) chloride product. Thus, water must be driven from the $\mathrm{VCl}_{3}$ prior to any further processing. $\mathrm{VCl}_{3}$ is known to readily dehydrate at $160{ }^{\circ} \mathrm{C}$; however hydrolysis forming vanadium oxide $\left(\mathrm{V}_{2} \mathrm{O}_{3}\right)$ can occur above $130^{\circ} \mathrm{C}$. ${ }^{\mathrm{f}}$ To address this issue, Knoche has successfully performed the dehydration at lower temperatures using a stripping gas stream of $\mathrm{N}_{2}$, mix of $\mathrm{N}_{2}$ and $\mathrm{HCl}$, and pure $\mathrm{HCl}$ gas. ${ }^{\mathrm{g}}$

In his patent application, Amendola reports two variants of the cycle. In the "dry" version, separations are needed including the removal of $\mathrm{O}_{2}$ from $\mathrm{HCl}$, and dehydration of the $\mathrm{VCl}_{3}$. The dry version consists of three reaction steps:
$2 \mathrm{VCl}_{3} \leftrightarrow 2 \mathrm{VCl}_{2}+\mathrm{Cl}_{2}$
$525^{\circ} \mathrm{C}$
eq 7
$\mathrm{Cl}(\mathrm{g})+\mathrm{H}_{2} \mathrm{O}(\mathrm{g}) \leftrightarrow 2 \mathrm{HCl}(\mathrm{g})+1 / 2 \mathrm{O}_{2}$ (Co catalyst)
$100^{\circ} \mathrm{C} \quad$ eq 8
$2 \mathrm{VCl}_{2}+2 \mathrm{HCl} \leftrightarrow 2 \mathrm{VCl}_{3}+\mathrm{H}_{2}$
$300^{\circ} \mathrm{C} \quad$ eq 9

In the "wet" variant, hydrogen is generated from an aqueous solution of $\mathrm{HCl}$ as shown in equations 10-12. The advantage of this process is that there is no need to remove $\mathrm{HCl}$ from $\mathrm{O}_{2}$ since the products of reverse Deacon reaction (eq 11) are condensed to accommodate the decomposition of $\mathrm{HCl}$ at $30^{\circ} \mathrm{C}$, as shown in eq 12 .
$2 \mathrm{VCl}_{3} \leftrightarrow 2 \mathrm{VCl}_{2}+\mathrm{Cl}_{2}$
$>525^{\circ} \mathrm{C} \quad$ eq 10
$\mathrm{Cl}(\mathrm{g})+\mathrm{H}_{2} \mathrm{O} \leftrightarrow 2 \mathrm{HCl}+1 / 2 \mathrm{O}_{2}$ (Co catalyst)
$300{ }^{\circ} \mathrm{C}$
eq 11
$2 \mathrm{VCl}_{2}+2 \mathrm{HCl}(\mathrm{aq}) \leftrightarrow 2 \mathrm{VCl}_{3}(\mathrm{aq})+\mathrm{H}_{2}$
$30^{\circ} \mathrm{C}$
eq 12

Although the "wet" process seems to be a potentially more functional cycle due to the obviation of needed chemical separations, it is lower in efficiency when the heat demand of the steam is factored in. In fact, the "dry" process is more efficient theoretically, as long as the outlined chemical separations can be performed using little energy.

\section{Magnesium-lodine Cycle}

The magnesium-iodine cycle is a four step purely thermochemical cycle based on the oxidation-reduction loops of magnesium and iodine, as shown in the following equations.
$6 / 5 \mathrm{MgO}(\mathrm{s})+6 / 5 \mathrm{I}_{2}$
$(1) \leftrightarrow 1 / 5 \mathrm{Mg}\left(\mathrm{IO}_{3}\right)_{2}$
$(\mathrm{s})+\mathrm{MgI}_{2}(\mathrm{aq})$
$120^{\circ} \mathrm{C}$
eq 13
$1 / 5 \mathrm{Mg}\left(\mathrm{IO}_{3}\right)_{2}(\mathrm{~s}) \leftrightarrow 1 / 5 \mathrm{MgO}$
(s) $1 / 5 \mathrm{I}_{2}(\mathrm{~g})+1 / 2 \mathrm{O}_{2}(\mathrm{~g})$
$600{ }^{\circ} \mathrm{C}$
eq 14

\footnotetext{
${ }^{\text {e }}$ K.F. Knoche, P.Shuster, "Thermochemical Production of Hydrogen by a Vanadium/Chlorine Cycle. Part 1: An Energy and Exergy Analysis of the Process", Int. J. Hydrogen Energy, 1984, 9(6), 457.

${ }^{\mathrm{f}}$ V.V. Pechovskii, N.L. Vorob'ev, “The Reaactions of Vanadium Chlorides with Hydrogen, Oxygen, and Water”, Russ.J. Inorg. Chem. 1984, 10, 778.

${ }^{\mathrm{g}}$ K.F. Knoche, P. Shuster, T. Ritterbex, "Thermochemical Production of Hydrogen by a Vanadium/Chlorine Cycle. Part 2: Experimental Investigation of the Individual Reaction”, Int. J. Hydrogen Energy, 1984, 9(6), 473.
} 
$\mathrm{MgI}_{2} \cdot 6 \mathrm{H}_{2} \mathrm{O}(\mathrm{s}) \leftrightarrow \mathrm{MgO}(\mathrm{s})+5 \mathrm{H}_{2} \mathrm{O}(\mathrm{g})+2 \mathrm{HI}(\mathrm{g})$

$2 \mathrm{HI}(\mathrm{g}) \leftrightarrow \mathrm{H}_{2}(\mathrm{~g})+\mathrm{I}_{2}(\mathrm{~g})$
$450{ }^{\circ} \mathrm{C}$

eq 15

$450{ }^{\circ} \mathrm{C}$

eq 16

In each of the four steps, there are requirements for chemical separations. In eq 13, it has been noted by Gadala-Maria (University of South Carolina) that the separation of $\mathrm{MgI}_{2}$ from the $\mathrm{Mg}\left(\mathrm{IO}_{3}\right)_{2}$ is not complete. Shindo et.al. determined that the concentration and the stoichiometry of the reaction is important to performing a clean conversion. ${ }^{\mathrm{h}}$ For instance, if the reaction is run with a relatively lower ratio of $\mathrm{I}_{2}$ to $\mathrm{MgO}$ under water limiting (concentrated) conditions, conversion to $\mathrm{Mg}\left(\mathrm{IO}_{3}\right)_{2}$ is poor and an undesired side reaction produced non-useful products. Increasing the $\mathrm{I}_{2} / \mathrm{MgO}$ ratio and keeping the solution of $\mathrm{MgI}_{2}$ diluted to $40-50 \%$ eliminates the side product and gives anhydrous $\mathrm{Mg}\left(\mathrm{IO}_{3}\right)_{2}$ in $80-90 \%$ yield. The separation of the iodate from the iodide is simple filtration due to the fact that the iodate precipitates. However this separation is not complete and some iodate remained in solution. To address this problem, Gadal-Maria is considering electrodialysis.

Separation of the $\mathrm{MgI}_{2}$ solution is required to provide the feed to eq 15. This solution, once iodate is removed, consists of leftover iodine, $\mathrm{MgI}_{2}$, and water. Shindo discussing using simple distillation under ambient pressure to drive off both the water and iodine as vapors, which can be separated by condensation.

In eq 14, there is a need to separate $\mathrm{O}_{2}$ from iodine. Condensation of the iodine can be easily performed through cooling of the product stream. Recycle of the iodine to eq 13 could be done below the boiling point of iodine $\left(184{ }^{\circ} \mathrm{C}\right)$ allowing effective removal of $\mathrm{O}_{2}$ at this point.

In eq 15 , an aqueous solution of $\mathrm{HI}$ is formed that must be concentrated prior to the $\mathrm{HI}$ decomposition (eq 16). This separation can be problematic due to the azeotrope that exists at 57 $\% \mathrm{HI}$ content. Techniques such as distillation cannot be used to further concentrate the HI solution. This is a problem that exists is the S-I process and has been addressed using three approaches, albeit the S-I issue is further complicated by the elemental iodine content. First, reactive distillation is a process in which hydrogen is directly generated by decomposition of $\mathrm{HI}$ without significant concentration or removal of iodine, which of course is not an issue for the $\mathrm{Mg}-\mathrm{I}$ cycle. Second, extractive distillation is a two step process that uses added concentrated phosphoric acid into $\mathrm{HI}_{\mathrm{x}}$ (iodine containing aqueous $\mathrm{HI}$ ) which allows for extraction and recycle of iodine. ${ }^{\text {i }}$ The resulting HI, phosphoric acid, and water solution is distilled to obtain concentrated HI. Third, membrane processes for direct removal of water from HI solutions has been studied. ${ }^{\mathrm{j}, \mathrm{k}}$ In this work, pervaporation was used to concentrate HI by selective removal of water using Nafion ${ }^{\circledR}$ membranes. Later work has revealed that HI may be concentrated up to 80 $\%$ at temperatures as high as $140{ }^{\circ} \mathrm{C}$ using this process. Once the $\mathrm{HI}$ is sufficiently concentrated,

\footnotetext{
${ }^{\text {h }}$ Y. Shindo, N.Ito, K.Haraya, T. Hakuta, H. Yoshitome, "Thermal Efficiency of the Magnesium-Iodine Cycle for Thermochemical Hydrogen Production”, Int. J. Hydrogen Energy, 1983, 7, 509.

i J.H. Norman, G.E. Besenbruch, D.R. O’Keefe, “Thermochemical Water-Splitting for Hydrogen Production”, Report \# GRI80/0105, March 1981.

${ }^{\mathrm{j}}$ C. J. Orme, M. G. Jones, and F. F. Stewart, "Pervaporation of Water from Aqueous HI using Nafion ${ }^{\circledR}-117$ Membranes for the Sulfur-Iodine Thermochemical Water Splitting Process”, J. Membr. Sci. 2005252 (1-2), 245.

${ }^{k}$ F. F. Stewart, C. J. Orme, M. G. Jones, “Membrane Processes for the Sulfur-Iodine Thermochemical Cycle”, Int. J. Hydrogen Energy 2007, 32, 457-462.
} 
it may be dissociated over a catalyst to yield hydrogen. Early reports ${ }^{1}$ have studied catalysts such as platinum on carbon; however later work has shown that activated carbon is also effective. ${ }^{\mathrm{m}}$

\section{Copper-Chlorine Cycle}

Lewis discusses the Copper-Chlorine cycle in terms of two variants. The first involves four reactions as shown below:

$$
\begin{array}{lcr}
2 \mathrm{CuCl}(\mathrm{aq}) \leftrightarrow \mathrm{CuCl}_{2}(\mathrm{aq})+\mathrm{Cu}(\mathrm{s}) & 25^{\circ} \mathrm{C} & \text { eq } 17 \\
2 \mathrm{Cu}(\mathrm{s})+2 \mathrm{HCl}(\mathrm{g}) \leftrightarrow 2 \mathrm{CuCl}(\mathrm{l})+\mathrm{H}_{2}(\mathrm{~g})(\text { electrochemical) } & 450{ }^{\circ} \mathrm{C} & \text { eq } 18 \\
2 \mathrm{CuCl}_{2}(\mathrm{~s})+\mathrm{H}_{2} \mathrm{O}(\mathrm{g}) \leftrightarrow \mathrm{Cu}_{2} \mathrm{OCl}_{2}(\mathrm{~s})+2 \mathrm{HCl}(\mathrm{g}) & 350-375^{\circ} \mathrm{C} & \text { eq } 19 \\
\mathrm{Cu}_{2} \mathrm{OCl}_{2}(\mathrm{~s}) \leftrightarrow 2 \mathrm{CuCl}(\mathrm{l})+1 / 2 \mathrm{O}_{2}(\mathrm{~g}) & 450-550{ }^{\circ} \mathrm{C} & \text { eq } 20
\end{array}
$$

In this variant, hydrogen is generated from the electrochemical oxidation of copper to yield $\mathrm{Cu}^{1+}$, which is subsequently oxidized to $\mathrm{Cu}^{2+}$ and reduced to $\mathrm{Cu}$ metal in aqueous solution, as shown in eq 17. Combining of these two steps provides eq 21 , which directly generates hydrogen from $\mathrm{CuCl}$ in an electrochemical process.

$2 \mathrm{CuCl}(\mathrm{aq})+2 \mathrm{HCl} \leftrightarrow \mathrm{CuCl}_{2}(\mathrm{aq})+\mathrm{H}_{2}(\mathrm{~g})$ (electrochemical) $\quad 25^{\circ} \mathrm{C} \quad$ eq 21

The choice of which variant that will be the most efficient depends on the development of the electrochemical step in terms of cell voltage and current density, which has not been completely performed at this time.

Parasitic reduction of $\mathrm{CuCl}_{2}$ to $\mathrm{CuCl}$ during reaction 19 is an issue that has been raised. In this reduction, $\mathrm{Cl}_{2}$ is generated and the reincorporation of this material into the cycle represents an additional reaction step that must be addressed. If it were chosen to not recycle this chlorine, separation of this gas from $\mathrm{HCl}$ could be problematic if it were judged to be necessary. It is not clear whether reaction 20 is possible in the presence of excess $\mathrm{Cl}_{2}$.

Incomplete conversion in eq 17 will also lead to aqueous mixtures of $\mathrm{Cu}^{1+}$ and $\mathrm{Cu}^{2+}$, along with the desired $\mathrm{Cu}^{0} . \mathrm{Cu}^{0}$ precipitates from solution, thus obviating a separation step; however the separation of $\mathrm{Cu}$ ions is somewhat more problematic. Perhaps the most effective solution would be to modify the reaction conditions such that conversion is enhanced. Otherwise, selective absorbents for divalent cations could be employed.

\footnotetext{
${ }^{1}$ Y.Oosawa, "The Decomposition of Hydrogen Iodine and Separation of the Products by the Combination of an Adsorbent with Catalytic Activity and Temperature-swing Method”, Bull Chem. Soc. Jpn., 1981, 54, 2908.

${ }^{\mathrm{m}}$ D. M. Ginosar, Private communication.
} 


\section{Calcium-Bromine Cycle}

The calcium-bromine cycle is a three step cycle using an electrolytic hydrogen generation step where $\mathrm{HBr}$ is dissociated. The three steps are shown below:

$$
\begin{array}{lcr}
\mathrm{CaO}+\mathrm{Br}_{2}(\mathrm{~g}) \leftrightarrow \mathrm{CaBr}_{2}+1 / 2 \mathrm{O}_{2}(\mathrm{~g}) & 740{ }^{\circ} \mathrm{C} & \text { eq } 22 \\
3 \mathrm{CaBr}_{2}(\mathrm{l})+\mathrm{H}_{2} \mathrm{O}(\mathrm{g}) \leftrightarrow\left(\mathrm{CaBr}_{2}\right)_{2} \cdot \mathrm{CaO}(\mathrm{s})+2 \mathrm{HBr}(\mathrm{g}) & 550{ }^{\circ} \mathrm{C} & \text { eq } 23 \\
2 \mathrm{HBr} \leftrightarrow \mathrm{Br}_{2}(\mathrm{~g})+\mathrm{H}_{2}(\mathrm{~g}) \text { (electrochemical) } & 55^{\circ} \mathrm{C} & \text { eq } 24
\end{array}
$$

In this cycle, $\mathrm{HBr}$ is regenerated from the reaction of $\mathrm{CaBr}_{2}$ with water, and $\mathrm{CaBr}_{2}$ is prepared from $\mathrm{CaO}$ using the bromine generated from the electrochemical step. Lewis indicates that none of the chemical separations required for this cycle are difficult; however they do require some attention. First, drying of the $\mathrm{CaBr}_{2}$ hydrolysis product $(\mathrm{HBr})$ could improve the overall efficiency of the process; however the electrochemical step is not stopped by the inclusion of some water. This separation most likely can be done using a membrane; however the temperature must be lowered significantly. Proven membrane technologies for de-watering acidic solutions function only up to about $150^{\circ} \mathrm{C}$. Higher temperatures lead to membrane degradation and technologies that can withstand higher temperatures, in general, would not be expected to exhibit selectivity in this separation.

\section{Summary}

None of the cycles discussed above have separations that are potential "show stoppers"; although some of the indicated separations will be challenging to perform. For example, the separation of $\mathrm{O}_{2}$ from $\mathrm{Br}_{2}$ at $740{ }^{\circ} \mathrm{C}$ as indicated in the Calcium Bromide cycle may be difficult due to the gaseous nature of these two components. This issue is magnified due to the temperature involved in this particular step. Additionally, the separation of $\mathrm{Cu}$ ions discussed as a part of the Copper-Chlorine cycle also poses challenges; although a sorption technique specific for divalent cations may have utility.

The majority of the separations involve separations that are either more achievable or more developed. For the Magnesium-Iodine cycle, many of the required separations are also common with the more developed Sulfur-Iodine, thus a targeted research effort may not be required. Furthermore, the oxygen separation required for the Hybrid Chlorine cycle should be able to be performed using existing mixed metal oxide membranes that have shown good selectivity favoring oxygen. 